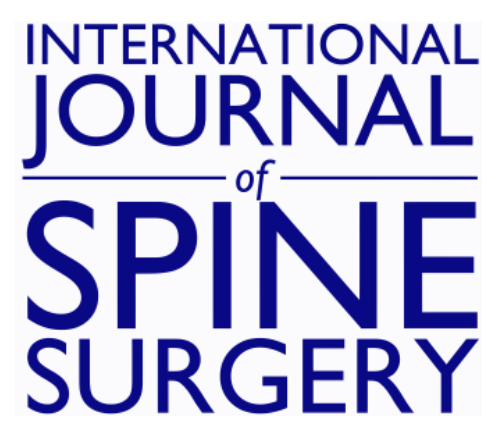

\title{
Minimal Clinically Important Difference in Patient-Reported Outcome Measures with the Transforaminal Endoscopic Decompression for Lateral Recess and Foraminal Stenosis
}

KAI-UWE LEWANDROWSKI, PAULO SÉRGIO TEIXEIRA DE CARVALHO, PAULO DE CARVALHO, JR and ANTHONY YEUNG

Int J Spine Surg 2020, 14 (2) 254-266

doi: https://doi.org/10.14444/7034

http://ijssurgery.com/content/14/2/254

This information is current as of April 26, 2023.

Email Alerts Receive free email-alerts when new articles cite this article. Sign up at: http://ijssurgery.com/alerts 


\title{
Minimal Clinically Important Difference in Patient-Reported Outcome Measures with the Transforaminal Endoscopic Decompression for Lateral Recess and Foraminal Stenosis
}

\author{
KAI-UWE LEWANDROWSKI, MD ${ }^{1}$ PAULO SÉRGIO TEIXEIRA DE CARVALHO, MD, PHD, ${ }^{2}$ \\ PAULO DE CARVALHO JR, MD, ${ }^{3}$ ANTHONY YEUNG, MD ${ }^{4}$ \\ ${ }^{1}$ Center for Advanced Spine Care of Southern Arizona and Surgical Institute of Tucson, Arizona; Visiting Professor Department of Orthopaedics, Fundación \\ Universitaria Sanitas, Bogotá, D.C., Colombia ${ }^{2}$ Department of Neurosurgery, Universidade Federal do Estado do Rio de Janeiro, Rio de Janeiro, Brazil \\ ${ }^{3}$ Department of Neurosurgery, KRH Hospital Nordstadt, Hannover, Germany ${ }_{4}^{4}$ University of New Mexico School of Medicine Department of Neurosurgery \\ Albuquerque, New Mexico; Desert Institute for Spine Care, Phoenix, Arizona
}

\begin{abstract}
Background: Patient-reported outcome measures (PROMs) have become widely used to better measure patients' judgment of treatment benefits from surgical spine care. The concept of determining the minimal clinically important differences (MCIDs) of PROMs is aimed at assessing the benefits of lumbar spine care that are meaningful to the patient. The goal of this study was to validate the utility of MCIDs of the visual analog score (VAS) and Oswestry Disability Index (ODI) in patients with sciatica-type low back and leg pain due to lateral recess and foraminal stenosis who were treated with directly visualized transforaminal outpatient endoscopic decompression.

Methods: The retrospective study population consisted of 406 patients on whom PROMs were obtained preoperatively, and again postoperatively at final follow-up. Employing an anchor-based approach with a patient satisfaction index based on the modified Macnab criteria, a receiver operating characteristics (ROC) and area under the curve (AUC) analysis was performed using IBM SPSS 25.0 to define the optimal MCID in VAS and ODI with the transforaminal endoscopy using the top-left-corner criteria and the Youden index. Improvements in walking endurance were recorded as an additional parameter of patient functioning and correlated with PROMs to test for statistical significance.

Results: The patients' average age was 41.08 years, ranging from 30 to 84 years. The mean follow-up was 33.59 months, ranging from 24 to 85 months, with a standard deviation of 12.79. The MCIDs for VAS and ODI were 2.5 to 3.5 and 15 to 16.5, respectively. Patients were dichotomized as improved (377/406; 92.9\%) if they reported excellent $(224 / 406 ; 55.2 \%)$, good $(112 / 406 ; 27.6 \%)$, and fair $(41 / 406 ; 10.1 \%)$ Macnab outcomes. Patients were dichotomized as failed if they reported poor (29/406; 7.1\%) Macnab outcomes. Preoperatively, only 32.5\% (132/406) of patients had unlimited walking endurance compared to $77.6 \%$ (315/406) of patients postoperatively. The ROC and AUC analysis showed better accuracy with the single-integer VAS score (0.926) than with the 10-item ODI score $(0.751)$.

Conclusions: Transforaminal outpatient endoscopic decompression for symptomatic foraminal and lateral recess stenosis is an effective surgical treatment to alleviate sciatica-type and back symptoms in $92.9 \%$ of patients. Of the PROMs analyzed, the VAS provided a more meaningful and accurate reflection of patients' interpretation of outcome with the transforaminal endoscopic spinal decompression procedure than ODI. Understanding which patient expectations drive these MCIDs may aid in replacing open surgeries for sciatica-type low back and leg pain currently preferred by traditional spine surgeons with a personalized early-staged transforaminal endoscopic hybrid decompressive/ablative procedures favored by the authors. These may prove more cost effective by focusing on significant pain generators validated with a diagnostic interventional workup instead of employing image-based indication criteria for surgery.
\end{abstract}

Minimally Invasive Surgery

Keywords: minimally clinically important differences, patient reported outcomes, endoscopic transforaminal decompression, VAS, ODI

\section{INTRODUCTION}

Making a case for transforaminal endoscopic spinal decompression surgery for a lumbar herniated disc or foraminal stenosis causing sciatica- type low back and leg pain hinges on providing comparative clinical evidence to alternative translaminar decompression surgeries. The commonly used patient-reported outcome measures (PROMs) include the visual analog score $(\mathrm{VAS})^{1-12}$ and the 
Oswestry Disability Index (ODI).${ }^{13-18}$ Understanding the ability of these PROM scores to detect changes in health status in response to an intervention meaningful to the patient is critical to support conclusions in favor of one treatment over another. While PROMs were designed to more directly involve patients in their care and improve their participation in the judgment of its outcomes, the minimal clinically important difference score (MCID) was developed by Jaeschke et $\mathrm{al}^{19}$ in 1989 in an attempt to deal with the problem that analysis of a PROM instrument measuring change after intervention in some cases may show statistical significance without any clinical relevance. Therefore, MCID is determined as the threshold value of a spine care outcome instrument that spine surgeons and their patients perceive as clinically meaningful.

With endoscopic spinal surgery moving more into the mainstream, ${ }^{4,5,9-11,13,20-35}$ the debate on its longterm clinical outcomes and recommended indications will likely intensify. It may be fueled by technology advancements but more likely by innovative spine surgeons who advocate to replace traditional lumbar open translaminar with transforaminal endoscopic decompression surgeries on the merits of improved outcomes, and lower cost due to fewer peri- and postoperative complications and reoperations. In the hands of a well-trained and experienced endoscopic spine surgeon, this outpatient procedure is associated with an overall lower burden to patients, and excellent long-term durability of favorable outcomes, especially since the procedure can be performed under local anesthesia and eliminate the use of general anesthesia. ${ }^{29}$ The authors of this study stipulated that the MCIDs for VAS and ODI as a result of the outpatient transforaminal endoscopic decompression may be different from those published ${ }^{36-52}$ for open translaminar decompression as the perception of its clinical benefit well known to patients is driven by the stark differences between the two procedures: a clean small stab versus an open incision with risk of infection, in most cases an outpatient procedure at an ambulatory surgery center) under local anesthesia versus an inpatient surgery at a hospital, minimal bleeding and incisional discomfort versus wound pain with potential for blood loss, and, last but not least, faster recovery and social reintegration versus longer narcotic dependence, delayed return to work, and higher direct and indirect cost. With the advent of the internet and social media this easy-tounderstand context of improved standards of care with the endoscopic over traditional translaminar surgery is becoming common knowledge among patients and one wonders how patient perception and, hence, the respective MCID threshold values are impacted by these trends. It is well known that MCIDs are not static numbers and are heavily influenced by a myriad of patient demographic factors, the individual baseline severity of the disease, and the dynamic of a recall bias of the intrinsic nature of their prior condition while comparing the current functional status against expectations which are heavily impacted by the public discourse about contemporary minimally invasive spine surgery techniques. Moreover, MCIDs are also influenced by the type of procedure performed.

One crucial premise for endoscopic spine procedures primarily offered for pain and symptom reduction is the concept of a staged surgical procedure that typically provides more effective and longer-lasting symptom relief when compared to nonsurgical and pain management ablation options, which by their nature are intended as an intermediate step before considering surgery by providing a temporary reduction of symptom. ${ }^{29}$ Traditionally trained spine surgeons are often focused on employing image-based threshold criteria to define the surgical indication for correcting symptoms stemming from spinal stenosis, deformity, and instability. Traditional surgical spine care tends to be more expensive and associated with higher perioperative risk since definitive treatment tends to be directed at the patients' symptoms when the degenerative spine disease has reached its end stage by performing an aggressive salvage surgery that often involves instrumented fusion. The concept of early and staged surgical pain management with an endoscopically visualized treatment of established and validated pain generators is getting traction amongst those spine surgeons who recognize the need for a paradigm shift toward more personalized and cost-effective spine care to meet the demands by patients and payors alike. This ongoing paradigm shift, however, creates an entirely new clinical context of spine care for patients and surgeons who provide it. Therefore, the authors decided to take a fresh look at MCIDs with VAS and ODI in transforaminal endoscopic spinal surgery patients in an attempt to validate these 


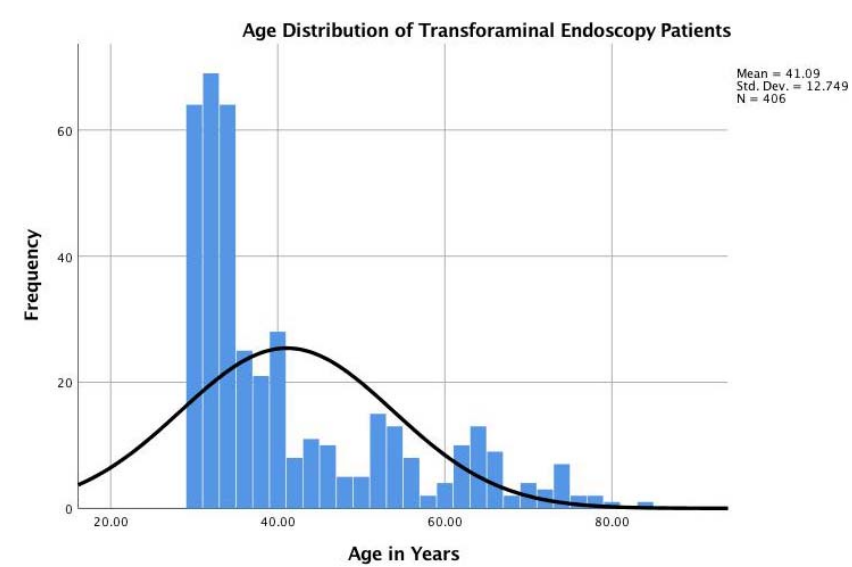

Figure 1. Age distribution of the 406 study patients with the superimposed expected normal distribution if it existed (black line). Patient's age ranged from 30 to 84 years of age and averaged 41.08 years with an SD of 12.74 . There was with a trimodal distribution with patients between the ages of 30 and 35 years making up $53.8 \%$ of the entire study population (frequency table not shown). The second largest group of patients was between the ages of 39 to 46 years of age $(13.9 \%$ of study population) followed by third group of patients between the ages of 51 to 65 of years (17.6\% of study population).

commonly used PROMs with the intent to improve the clinicians' ability to identify those endoscopic treatments of common painful conditions of the lumbar spine associated with better clinical outcomes when directly compared with traditional open translaminar surgeries.

\section{MATERIALS AND METHODS}

\section{Patients}

All 406 consecutive patients included in this retrospective study were treated between 2012 and 2017 for claudication sciatica-type low back and leg pain due to contained herniated disc with or without bony and soft tissue lateral recess and foraminal stenosis due to age-related degeneration of the spinal motion segment demonstrated on preoperative magnetic resonance imaging (MRI). The associated lumbar disc herniations, facet joint hypertrophy, and the overall ligamentous and bony overgrowth was treated with a directly visualized outpatient endoscopic transforaminal decompression procedure in an ambulatory surgery center which often employs an initial foraminoplasty to gain access to the triangular safe zone between the exiting and traversing nerve root. The procedural details employed by the authors have been described elsewhere. ${ }^{1,2,17,18,53,54}$ All patients sought out the endoscopic spine surgeons who authored this study and provided informed consent. Patients were matched to age, gender, and diagnosis to avoid the introduction of additional confounding factors or

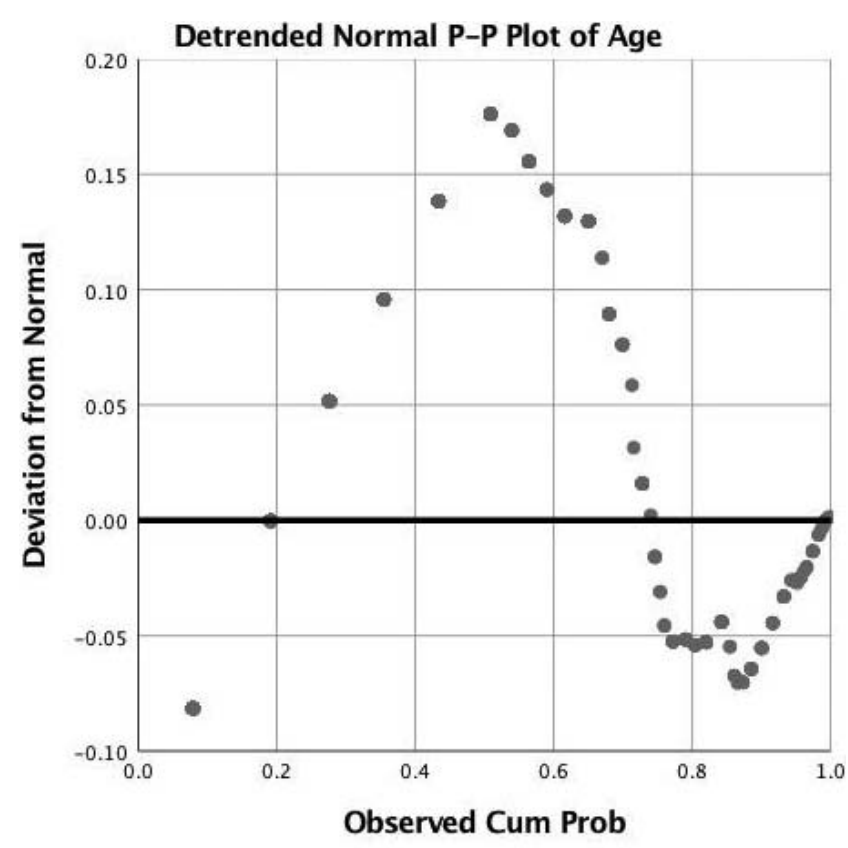

Transforms: natural logarithm

Figure 2. The trimodal age distribution of the 406 study patients is illustrated in the detrended normal P-P plot of endoscopy patients' age with an estimated location parameter of 3.67 .

unforeseen biases. The mean follow-up was 33.59 months, ranging from 24 to 85 months, with a standard deviation (SD) of 12.79. The mean age was 41.08 years ranging from 30 to 84 years with an SD of 12.74 with a trimodal distribution (Figures 1 and 2) with patients between the ages of 30 and 35 years making up $53.8 \%$ of the entire study population. The second-largest group of patients was between the ages of 39 to 46 years of age (13.9\% of the study population), followed by the third group of patients between the ages of 51 to 65 of years $(17.6 \%$ of the study population). There were 229 females $(56.4 \%)$ and 177 males $(43.6 \%)$ in the study population. The inclusion and exclusion criteria for this study have been published elsewhere ${ }^{29}$ in detail and are briefly described in the following section.

\section{Inclusion/Exclusion and Radiographic Criteria}

Following a thorough history, physical examination, and evaluation of the preoperative MRI studies and failed nonoperative medical and interventional spine care for a minimum of 12 weeks, patients were selected for the transforaminal endoscopic decompression procedure. The size and location of the contained herniation in the spinal canal, and the height and width of the lateral recess and the neuroforamen, were graded and recorded according to well-established radiographic classifi- 
cation systems ${ }^{55,56,57,58}$ previously employed by the authors. ${ }^{17,53,54,59}$ In short, lumbar neuroforaminal height of $15 \mathrm{~mm}$ or less and a reduced neuroforaminal width (measured on the sagittal MRI cuts), lateral recess height of $3 \mathrm{~mm}$ or less (measured on the axial MRI cuts), and posterior intervertebral disc height of 3 or less were graded as abnormal. ${ }^{58}$ Patients with multilevel disease were considered for additional interventional workup using a transforaminal selective nerve root block protocol described elsewhere to determine the most symptomatic level best suited for the transforaminal endoscopic decompression procedure. ${ }^{54}$ Patients with infection, tumor or metastatic disease, and spondylolisthesis were excluded. Patients with severe central stenosis $\left(<100 \mathrm{~mm}^{2}\right)$ were also excluded. ${ }^{60}$

\section{Transforaminal Endoscopic Surgical Technique}

Under direct visualization, the transforaminal endoscopic approach was chosen to access the neuroforamen and, ultimately, the lateral recess, employing the "outside-in" technique. ${ }^{17,61,62}$ After serial dilation, the working cannula was placed at the lateral aspect of the lumbar facet joints. An initial foraminoplasty using laser, kerrisons, trephines, and motorized drills was carried out in all patients to expose the herniation and to facilitate placement of the working cannula into the triangular safe zone formed by the exiting and traversing nerve root. A bipolar radiofrequency probe (Elliquence, Baldwin, New York) was used for control of bleeding, shrinkage, and ablation of disc annular tissue. $^{33,63}$ Intraoperative fluoroscopic image guidance was used during the visualized endoscopic decompression surgery to verify the surgical level and the position of the instruments in the spinal canal.

\section{Clinical Follow-Up \& PROM Analysis}

The success of the visualized transforaminal or endoscopic surgical decompression was evaluated using VAS and ODI as the primary PROMs. The VAS is a 10-digit integer score ranging from 0 (no pain) to 10 (worst pain imaginable). ${ }^{12}$ The ODI is a 10-item composite instrument assessing pain intensity, personal care, and function, including walking, lifting, personal care, sitting, standing, sleeping, social interaction, and traveling. ${ }^{64-67}$ Each ODI item is scored from 0 (no impairment) to 5 (worst impairment). The individual scores are summed and then multiplied by 2 to obtain the ODI index ranging from 0 to 100 . Only patients with complete responses were included in this study. For the application of the anchor-based approach for the MCID determination, a patient satisfaction index (PSI) based on a modification of the Macnab criteria was employed. ${ }^{68-70}$ At each follow-up visit and final follow-up, patients were asked to select 1 of the following 4 possible choices: (1) "The endoscopic surgery met my expectations, I have little pain, and I can perform desired activities with few limitations," excellent; (2) The endoscopic surgery met my expectations, I have occasional pain or sensory problems, but I can perform daily activities with minor limitations and do not take pain medication," good; (3) "The endoscopic surgery met my expectations, my pain is somewhat improved, but I continue to need pain medication," fair; and (4) "My expectations were not met by the endoscopic surgery; I am worse off or needed additional surgery," poor. The PSI was dichotomized considering responses 1 through 3 as improved and response 4 as failed. This PSI dichotomization was employed as the anchor approach in a receiver operating characteristic (ROC) analysis with the area under the curve (AUC) assessing the quality of the PROMs to measure of patient satisfaction as a result of the transforaminal endoscopic decompression procedure. The optimal MCID was calculated using the top-left-corner method and the Youden index using SPSS statistics software, Version 25.0 (IBM, Armonk, New York). Additional descriptive statistics included means, ranges, and standard deviations as well as percentages. Cross-tabulation statistics and measures of association were computed for 2-way tables. The Pearson $\chi^{2}$ and the likelihood-ratio $\chi^{2}$ tests were used as statistical measures of association using 95\% confidence intervals (CIs) and considering $P$ values of less than .05 as statistically significant.

At each follow-up visit, patients were asked whether they went to an emergency room for any unforeseen postoperative problems or whether they were admitted to a hospital for any complications or sequelae (unavoidable problems following an expertly executed surgery). Some patients needed supportive care measures for postoperative irritation of the dorsal root ganglion with nonsteroidal anti-inflammatories, gabapentin, and transforaminal epidural steroid injections. Postoperative phys- 
Table 1. VAS and ODI paired samples statistics $(\mathrm{N}=406)$.

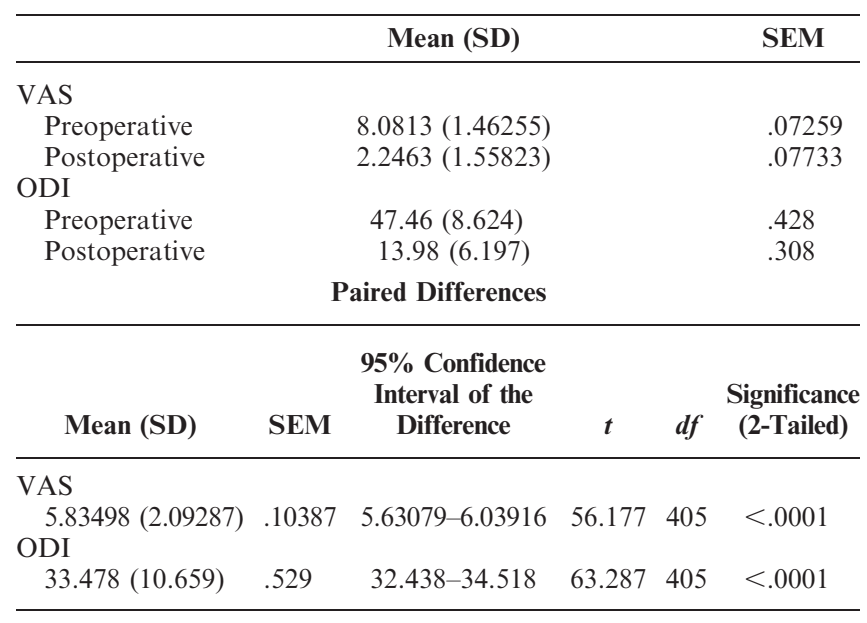

Abbreviations: VAS, visual analog score; ODI, Oswestry Disablity Index.

ical rehabilitation was not routinely ordered, as most patients mobilized readily.

\section{RESULTS}

The 406 patients who underwent an endoscopic transforaminal decompression procedure reported significant reductions of the mean \pm SD VAS from preoperative $(8.0813 \pm 1.46255)$ to postoperative $(2.2463 \pm 1.55823)$ values $(P<.0001$; Table 1$)$ on paired $t$ testing. Similar statistically significant reductions were observed from the preoperative ODI of $47.46 \pm 8.624$ to a postoperative ODI $13.98 \pm 6.197(P<.0001)$. Patients rated how their expectations were met by the achieved clinical outcomes from the transforaminal endoscopic decompression procedure by selecting one of the following PSI options with the following frequency: excellent, 224 patients $(55.2 \%)$; good, 112 patients $(27.6 \%)$; fair, 41 patients $(10.1 \%)$; and poor, 29 patients $(7.1 \%)$. The dichotomized PSI results showed 377 patients $(92.9 \%)$ as improved, and the remaining 29 patients $(7.1 \%)$ as failed (Table 2). Preoperatively, 31.3\% (137) of the 406 study patients had a significant limitation of walking endurance of fewer than $300 \mathrm{~m}$, whereas $50.2 \%$ (214) of patients could not walk farther than $500 \mathrm{~m}$ (Table 3). Only 132 patients $(32.5 \%)$ were essentially able to walk without limitations by indicating that their walking endurance was higher than $5000 \mathrm{~m}$. Postoperatively, the overwhelming majority of patients $(315 / 406 ; 77.6 \%)$ indicated unlimited walking endurance $(\geq 5000 \mathrm{~m})$, a statistically significant improvement on paired $t$ testing $(P<.0001$; Table 3$)$. Cross-tabulation of dichotomized PSI versus walking endurance showed that
Table 2. Outcomes by modified MacNab criteria, and dichotomized PSI $(\mathrm{N}=$ 406).

\begin{tabular}{lrrrc}
\hline \multicolumn{2}{c}{ Frequency } & \% & Valid \% & Cumulative \% \\
\hline MacNab outcomes & & & & \\
Excellent & 224 & 55.2 & 55.2 & 55.2 \\
Good & 112 & 27.6 & 27.6 & 92.9 \\
Fair & 41 & 10.1 & 10.1 & 65.3 \\
Poor & 29 & 7.1 & 7.1 & 100.0 \\
$\quad$ Total & 406 & 100.0 & 100.0 & \\
Dichotomized PSI & & & & \\
Improved & 377 & 92.9 & 92.9 & 92.9 \\
Failed & 29 & 7.1 & 7.1 & 100.0 \\
Total & 406 & 100.0 & 100.0 & \\
\hline
\end{tabular}

Abbreviation: PSI, patient satisfaction index.

of the 377 improved patients, 69 patients were able to walk up to $1000 \mathrm{~m}$, and the remaining 299 improved patients were able to walk more than $5000 \mathrm{~m}$. More than half $(16 / 29)$ of the failed patients were also able to walk more than $5000 \mathrm{~m}$ after their successful transforaminal endoscopic decompression procedure. These differences in walking endurance between improved- and failedpatient dichotomized PSI ratings were statistically significant $(P=.002)$.

The ROC curve for postoperative VAS scores given by patients who underwent outpatient transforaminal endoscopic decompression surgery is shown in Figure 3. The AUC individual test results for postoperative VAS are listed in Tables $5 \mathrm{~A}$ and 5B. The AUC was 0.926, with an asymptotic $95 \%$ CI lower limit of 0.882 and an upper limit of 0.97 . The ROC curve for postoperative ODI scores given by the same patients is shown in Figure 4. The AUC individual test results for postoperative ODI are listed in Tables 6A and 6B. The AUC was 0.751, with an asymptotic $95 \%$ CI lower limit of 0.663 and an upper limit of 0.840 . The VAS MCID and ODI MCID values using Youden optimization for equally important sensitivity and specificity were 3.0 and 15 , respectively. Left-upper-corner methodology indicated a range of VAS MCIDs from 2.5 to 3.5 and of ODI MCIDs of 14 to 17 to be practical with the highest sensitivity and lowest false positive rate (Tables 5A, 5B and $6 \mathrm{~A}, 6 \mathrm{~B}$ ).

Pearson $\chi^{2}$ testing and cross-tabulation of the postoperative VAS score with postoperative walking endurance for the 3 age groups identified in the examination of the age distribution of endoscopy patients of this study (Table 7) showed a statistically significant asymmetric distribution of low VAS scores ranging from 0 to 2 in patients 30 to 35 years of age $(P=.013), 36$ to 47 years of age $(P=$ $.009)$, and 47 to 84 years of age $(P=.023)$. These 
Table 3. Preoperative and postoperative walking endurance in patients who underwent endoscopic decompression.

\begin{tabular}{|c|c|c|c|c|c|}
\hline Walking Endurance, $\mathrm{m}$ & Frequency & $\%$ & \multicolumn{2}{|c|}{ Valid \% } & Cumulative $\%$ \\
\hline \multicolumn{6}{|l|}{ Preoperative } \\
\hline 50 & 30 & 7.4 & \multicolumn{2}{|c|}{7.4} & 9.9 \\
\hline 100 & 30 & 7.4 & \multicolumn{2}{|c|}{7.4} & 17.2 \\
\hline 200 & 1 & .2 & \multicolumn{2}{|c|}{.2} & 17.5 \\
\hline 300 & 56 & 13.8 & \multicolumn{2}{|c|}{13.8} & 31.3 \\
\hline 500 & 77 & 19.0 & \multicolumn{2}{|c|}{19.0} & 50.2 \\
\hline 1000 & 70 & 17.2 & \multicolumn{2}{|c|}{17.2} & 67.5 \\
\hline$>5000$ & 132 & 32.5 & \multicolumn{2}{|c|}{32.5} & 100.0 \\
\hline$\overline{\mathrm{T}}$ otal & 406 & 100.0 & \multicolumn{2}{|c|}{100.0} & \\
\hline \multicolumn{6}{|l|}{ Postoperative } \\
\hline 500 & 9 & 2.2 & \multicolumn{2}{|c|}{2.2} & 2.2 \\
\hline 1000 & 82 & 20.2 & \multicolumn{2}{|c|}{20.2} & 22.4 \\
\hline$\geq 5000$ & 315 & 77.6 & \multicolumn{2}{|c|}{77.6} & 100.0 \\
\hline Total & 406 & 100.0 & \multicolumn{2}{|c|}{100.0} & \\
\hline \multicolumn{6}{|c|}{ Paired Samples } \\
\hline Mean (SD) & SEM & $\begin{array}{l}95 \% \text { Confidence } \\
\text { Interval of the Difference }\end{array}$ & $t$ & $d f$ & $\begin{array}{l}\text { Significance } \\
\text { (2-Tailed) }\end{array}$ \\
\hline$-44.974(50.870)$ & 2.525 & -49.937 to -40.011 & -17.814 & 405 & $<.0001$ \\
\hline
\end{tabular}

low VAS score patients were constituted mostly by patients with a walking endurance of greater than $5000 \mathrm{~m}$. An analogous cross-tabulation for the ODI reported by endoscopy patients showed a similar asymmetric but not statistically significant distribution with the majority of patients reporting ODI values between 5 to 19 a final follow-up (Table 8).

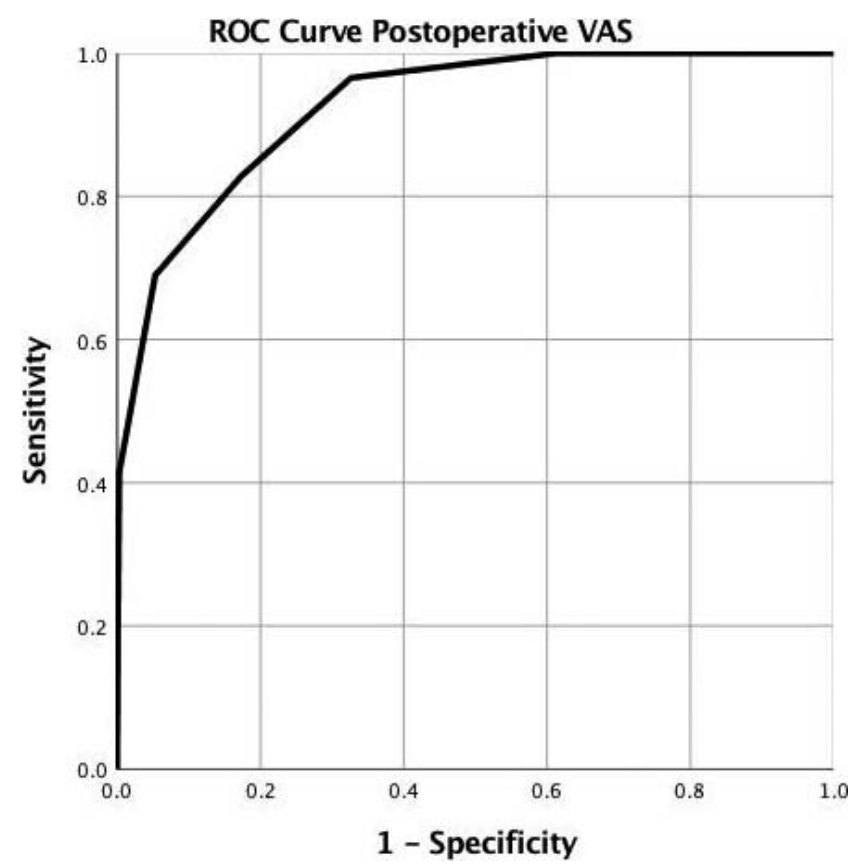

Figure 3. Receiver operating characteristic (ROC) curve for postoperative visual analog scale (VAS) scores given by patients who underwent outpatient transforaminal endoscopic decompression surgery. The area under the curve (AUC) individual test results for postoperative VAS are listed in Tables 5A and 5B. The AUC was 0.926 with an asymptotic $95 \%$ confidence interval lower limit of 0.882 and upper limit of 0.97 .

\section{DISCUSSION}

This study aimed to analyze the MCID score for VAS and ODI for the directly visualized transforaminal endoscopic lumbar decompression surgery in patients who suffered from lumbar foraminal and lateral recess soft tissue and bony stenosis. The purpose of the study was simple: to better delineate the utility of these 2 commonly used PROMs with the lumbar endoscopic spinal surgery for practical comparisons between spine outcome studies while taking patients' judgment of the treatment effect in the context of their expectations into account.

While there is little doubt that the directly visualized transforaminal endoscopic decompression techniques have become mainstream in most countries and are considered a viable alternative to both open and other types of minimally invasive translaminar decompression surgeries, ${ }^{4,5,9-11,13,20-35}$

Table 4. Postoperative walking endurance in patients who underwent endoscopic resection decompression versus dichotomized outcomes using the patient satisfaction index.

\begin{tabular}{|c|c|c|c|c|}
\hline $\begin{array}{l}\text { Postoperative } \\
\text { Walking Distance }\end{array}$ & $\begin{array}{l}\text { Up to } \\
500 \mathrm{~m}\end{array}$ & $\begin{array}{l}\text { Up to } \\
1000 \mathrm{~m}\end{array}$ & $\geq 5000 \mathrm{~m}$ & Total \\
\hline Improved & 9 & 69 & 299 & 377 \\
\hline Failed & 0 & 13 & 16 & 29 \\
\hline Total & 9 & 82 & 315 & 406 \\
\hline$\chi^{2}$ Tests & Value & $d f$ & \multicolumn{2}{|c|}{$\begin{array}{c}\text { Asymptotic } \\
\text { Significance (2-Sided) }\end{array}$} \\
\hline $\begin{array}{l}\text { Pearson } \chi^{2} \\
\text { Likelihood ratio } \\
\text { No. of valid cases }\end{array}$ & $\begin{array}{l}12.095^{\mathrm{a}} \\
10.703 \\
406\end{array}$ & $\begin{array}{l}2 \\
2\end{array}$ & \multicolumn{2}{|c|}{$\begin{array}{l}.002 \\
.005\end{array}$} \\
\hline
\end{tabular}

${ }^{\mathrm{a}} 1$ cells $(16.7 \%)$ have expected count less than 5 . The minimum expected count is .64 . 
Table 5A. AUC test for postoperative VAS. ${ }^{a}$

\begin{tabular}{cccc}
\hline Area & SE $^{\mathbf{b}}$ & Asymptotic Sig. & $\begin{array}{c}\text { Asymptotic } 95 \% \\
\text { Confidence Interval }\end{array}$ \\
\hline .926 & .022 & .000 & $.882-.970$ \\
\hline
\end{tabular}

Abbreviations: AUC, area under the curve; VAS, visual analog scale; sig., significance.

${ }^{\mathrm{a}}$ The test result variable(s): Postoperative VAS has at least one tie between the positive actual state group and the negative actual state group. Statistics may be biased.

${ }^{\mathrm{b}}$ Under the nonparametric assumption.

${ }^{\mathrm{c}}$ Null hypothesis: true area $=0.5$.

high-grade scientific clinical evidence is needed to consolidate its role in the treatment of spinal stenosis and herniated discs by replacing empiric knowledge with well-executed meaningful clinical trials. Making comparisons between such clinical trials relies on understanding the sensitivity, specificity, accuracy, and - as illustrated by this studyoptimal threshold values of the outcome instruments used to make a consequential distinction between treatments and study groups. Without such understanding, the most sophisticated study designs, such as those employing prospective randomization protocols, may be flawed from the outset and of little consequence to the day-to-day decision making by the individual practitioner despite statistical significance testing suggesting otherwise. Since patient satisfaction, or lack thereof, drives utilization in spine surgery and pain management, and treatment failures are instantly and always known to the patient who remains in pain and experiences disability with limited walking endurance due to neurogenic claudication, understanding the MCID for commonly used PROMs in the context of patients' expectations with each procedure is crucially important when making decisions for cost-effective, safe, and efficacious spine care.

In this situation, the concept of MCID is useful. However, it is complex and deserves further discussion as it should not be limited to a single

Table 5B. Coordinates of the curve for VAS.

\begin{tabular}{|c|c|c|}
\hline $\begin{array}{l}\text { Positive if Greater Than } \\
\text { or Equal } \mathrm{To}^{\mathrm{a}}\end{array}$ & Sensitivity & $\begin{array}{c}1-\text { Specificity } \\
\text { (False Positive Rate) }\end{array}$ \\
\hline-1.0000 & 1.000 & 1.000 \\
\hline .5000 & 1.000 & .873 \\
\hline 1.5000 & 1.000 & .613 \\
\hline 2.5000 & .966 & .326 \\
\hline 3.5000 & .828 & .172 \\
\hline 4.5000 & .690 & .053 \\
\hline 5.5000 & .414 & .003 \\
\hline 6.5000 & .034 & .000 \\
\hline 8.0000 & .000 & .000 \\
\hline
\end{tabular}

${ }^{\text {a }}$ The smallest cutoff value is the minimum observed test value minus 1 , and the largest cutoff value is the maximum observed test value plus 1 . All the other cutoff values are the averages of two consecutive ordered observed test values.

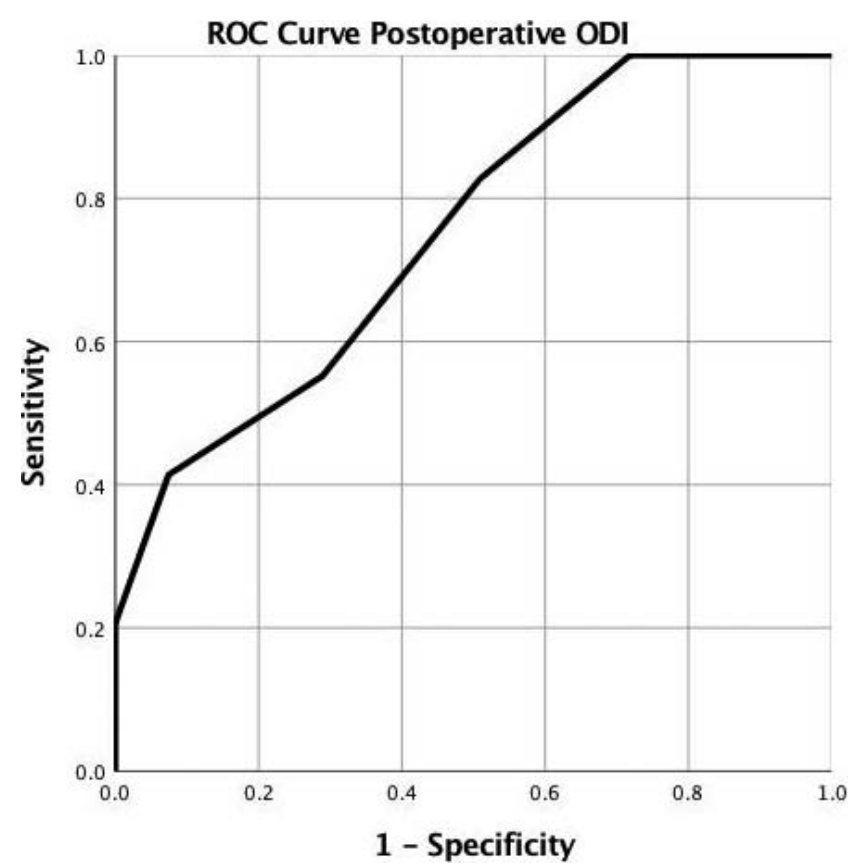

Figure 4. Receiver operating characteristic (ROC) curve for postoperative Oswestry Disablity Index (ODI) scores given by patients who underwent outpatient transforaminal endoscopic decompression surgery. The area under the curve (AUC) individual test results for postoperative ODI are listed in Tables $6 \mathrm{~A}$ and $6 \mathrm{~B}$. The AUC was 0.751 with an asymptotic $95 \%$ confidence interval lower limit of 0.663 and upper limit of 0.840 .

static number. In their original description, Jaeschke et $a{ }^{19}$ defined MCID as ".... the smallest difference in score in the domain of interest which patients perceive as beneficial and which would mandate, in the absence of troublesome side effects and excessive cost, a change in the patient's management."19 There are many ways to calculate MCIDs, and no single standard exists, making comparison methodologically challenging. For example, change in clinician reporting, disease state, clinical parameters, effect size, baseline and postintervention data from patients may be anchored to external criteria, such as the PSI used in this study, or to the measurement of internal values of another instrument (distribution approach). The VAS and ODI MCID analyses of this study were developed from patient data and relied on the patients to accurately reflect on improvements from the transforaminal

Table 6A. AUC test for postoperative ODI. ${ }^{a}$

\begin{tabular}{cccc}
\hline Area & SE $^{\mathbf{b}}$ & Asymptotic Sig. & $\begin{array}{c}\text { Asymptotic 95\% } \\
\text { Confidence Interval }\end{array}$ \\
\hline .751 & .045 & .000 & $.663-.840$
\end{tabular}

Abbreviations: AUC, area under the curve; ODI, Oswestry Disablity Index.

${ }^{\mathrm{a}}$ The test result variable(s): Postop ODI has at least one tie between the positive actual state group and the negative actual state group. Statistics may be biased.

${ }^{\mathrm{b}}$ Under the nonparametric assumption.

${ }^{\mathrm{c}}$ Null hypothesis: true area $=0.5$. 
Table 6B. Coordinates of the curve for ODI.

\begin{tabular}{lcc}
\hline $\begin{array}{l}\text { Positive if Greater Than } \\
\text { or Equal To }\end{array}$ & Sensitivity & $\begin{array}{c}\text { 1 }- \text { Specificity } \\
\text { (False Positive Rate) }\end{array}$ \\
\hline 4.00 & 1.000 & 1.000 \\
9.50 & 1.000 & .719 \\
14.50 & .828 & .509 \\
17.00 & .552 & .289 \\
21.50 & .414 & .074 \\
26.50 & .207 & .000 \\
30.00 & .000 & .000 \\
\hline
\end{tabular}

${ }^{a}$ The smallest cutoff value is the minimum observed test value minus 1 , and the largest cutoff value is the maximum observed test value plus 1 . All the other cutoff values are the averages of two consecutive ordered observed test values.

endoscopic decompression procedure from the preoperative baseline. As predicated by others, any seasoned spine surgeon knows that patients, instead of reporting improvements of their current health status in relation to their preoperative function, often make a comparison to their present-day expectations, ${ }^{71}$ or the functional status of their "normal" peers ${ }^{72}$ and fall victim to recall bias by failing to honestly remember the prior extent of

Table 7. Postoperative VAS score and walking endurance reported by patients who underwent endoscopic resection decompression in various age groups at final follow-up of 33.59 months.

\begin{tabular}{|c|c|c|c|c|}
\hline $\begin{array}{l}\text { Age Group, y, } \\
\text { and VAS Scale }\end{array}$ & $\begin{array}{l}\text { Up to } \\
500 \mathrm{~m}\end{array}$ & $\begin{array}{c}\text { Up to } \\
1000 \mathrm{~m}\end{array}$ & $\geq 5000 \mathrm{~m}$ & Total \\
\hline \multicolumn{5}{|l|}{$30-35$} \\
\hline 0 & 0 & 2 & 19 & 21 \\
\hline 1 & 0 & 8 & 48 & 56 \\
\hline 2 & 1 & 4 & 50 & 55 \\
\hline 3 & 3 & 8 & 26 & 37 \\
\hline 4 & 0 & 7 & 24 & 31 \\
\hline 5 & 1 & 5 & 6 & 12 \\
\hline 6 & 0 & 2 & 2 & 4 \\
\hline Subtotal & 5 & 36 & $17 \overline{5}$ & 216 \\
\hline \multicolumn{5}{|l|}{$36-46$} \\
\hline 0 & 0 & 2 & 10 & 12 \\
\hline 1 & 0 & 2 & 22 & 24 \\
\hline 2 & 0 & 3 & 16 & 19 \\
\hline 3 & 1 & 5 & 7 & 13 \\
\hline 4 & 1 & 1 & 3 & 5 \\
\hline 5 & 2 & 2 & 2 & 6 \\
\hline 6 & 0 & 2 & 2 & 4 \\
\hline 7 & 0 & 1 & 0 & 1 \\
\hline Subtotal & 4 & 18 & 62 & 84 \\
\hline \multicolumn{5}{|l|}{$47-84$} \\
\hline 0 & & 3 & 12 & 15 \\
\hline 1 & & 3 & 15 & 18 \\
\hline 2 & & 8 & 27 & 35 \\
\hline 3 & & 6 & 6 & 12 \\
\hline 4 & & 1 & 12 & 13 \\
\hline 5 & & 6 & 3 & 9 \\
\hline 6 & & 1 & 3 & 4 \\
\hline Subtotal & & 28 & 78 & 106 \\
\hline All ages & 9 & 82 & 315 & 406 \\
\hline Pearson $\chi^{2}$ & Value & $d f$ & \multicolumn{2}{|c|}{ Asymp. 2-Sided Sig. } \\
\hline $30-35$ y & 25.527 & 12 & \multicolumn{2}{|c|}{0.013} \\
\hline $36-46 y$ & 29.382 & 14 & \multicolumn{2}{|c|}{0.009} \\
\hline $47-84 \mathrm{y}$ & 14.710 & 6 & \multicolumn{2}{|c|}{0.023} \\
\hline
\end{tabular}

Abbreviations: VAS, visual analog scale; asymp. 2-sided sig., asymptotic 2-sided significance.
Table 8. Postoperative ODI score and walking endurance reported by patients who underwent endoscopic resection decompression in various age groups at final follow-up of 33.59 months.

\begin{tabular}{|c|c|c|c|c|}
\hline $\begin{array}{l}\text { Age Group, y, } \\
\text { and ODI Range }\end{array}$ & $\begin{array}{l}\text { Up to } \\
500 \mathrm{~m}\end{array}$ & $\begin{array}{c}\text { Up to } \\
1000 \mathrm{~m}\end{array}$ & $\geq 5000 \mathrm{~m}$ & Total \\
\hline \multicolumn{5}{|l|}{$30-35$} \\
\hline 5 & 0 & 6 & 49 & 55 \\
\hline 14 & 3 & 7 & 38 & 48 \\
\hline 15 & 2 & 6 & 40 & 48 \\
\hline 19 & 0 & 11 & 37 & 48 \\
\hline 24 & 0 & 5 & 10 & 15 \\
\hline 29 & 0 & 1 & 1 & 2 \\
\hline Subtotal & 5 & 36 & 175 & 216 \\
\hline \multicolumn{5}{|l|}{$36-46$} \\
\hline 5 & 0 & 4 & 21 & 25 \\
\hline 14 & 1 & 3 & 13 & 17 \\
\hline 15 & 2 & 3 & 13 & 18 \\
\hline 19 & 0 & 2 & 11 & 13 \\
\hline 24 & 1 & 6 & 3 & 10 \\
\hline 29 & 0 & 0 & 1 & 1 \\
\hline Subtotal & 4 & 18 & 62 & 84 \\
\hline \multicolumn{5}{|l|}{$47-84$} \\
\hline 5 & & 5 & 21 & 26 \\
\hline 14 & & 4 & 15 & 19 \\
\hline 15 & & 7 & 18 & 25 \\
\hline 19 & & 8 & 16 & 24 \\
\hline 24 & & 2 & 7 & 9 \\
\hline 29 & & 2 & 1 & 3 \\
\hline Subtotal & & 28 & 78 & 106 \\
\hline All ages & 9 & 82 & 315 & 406 \\
\hline Pearson $\chi^{2}$ & Value & $d f$ & \multicolumn{2}{|c|}{ Asymp. 2-Sided Sig. } \\
\hline $30-35 y$ & 14.582 & 10 & \multicolumn{2}{|c|}{0.148} \\
\hline $36-46 y$ & 15.302 & 10 & \multicolumn{2}{|c|}{0.121} \\
\hline $47-84 \mathrm{y}$ & 4.177 & 5 & \multicolumn{2}{|c|}{0.524} \\
\hline
\end{tabular}

Abbreviations: ODI, Oswestry Disability Index; asymp. 2-sided sig., asymptotic 2 sided significance.

their intrinsic spinal disability. ${ }^{73}$ Therefore, such a retrospective comparison renders the use of instruments, such as VAS and ODI, that query the amount of change from the preoperative baseline value, inherently imprecise.

Additionally, MCID values may also be influenced by the severity or extent of the baseline symptoms, ${ }^{74}$ as well as differences between age, education, or socioeconomic status of study populations. $^{75-77}$ The impact of these variations may carry forward and play out in expectation-driven patient response measures and therefore render different MCID values and ranges for different spine procedures. ${ }^{74}$ One of the most relevant and common problems, though, is the inability of patients to understand the context of improvement, ${ }^{78}$ a problem that may worsen with more complex or lengthy outcome instruments that consist of multiple questions with many multiplechoice answers. The ODI, for example, is a 10-item instrument versus the VAS being a single-integer instrument with responses ranging from 0 to 10 . The more complex ODI can induce more recall bias than 
the simple VAS score. One could contemplate how patients' understanding of the proper context of improvement may be more impaired with lengthier instruments, such as the SF-36. The ROC curve plots (Figures 3 and 4) and data (Tables 5A, 5B and $6 \mathrm{~A}, 6 \mathrm{~B})$ for both PROMs corroborated this problem. The AUC is equivalent to the percentage of randomly drawn pairs, which were correctly identified as having a determined outcome or not. Employing previously published criteria, ${ }^{79}$ the AUC analysis for both PROMs of this study showed that the single-integer VAS score had excellent accuracy (area 0.926; Table 5A) compared to the ODI, which produced only fair accuracy (area 0.751; Table 6A) in assessing MCID with the transforaminal endoscopic decompression procedure.

The MCID data of this study were anchored in the PSI, which was based on the modified Macnab criteria, a well-validated outcome instrument employed in countless endoscopic spine surgery outcome studies. ${ }^{6}$ The analysis of dichotomized PSI showed postoperative improvement in $92.9 \%$ (Table 2) of patients who underwent the transforaminal endoscopic decompression procedure. The PROMs employed in this study showed statistically significant reductions $(P<.0001)$ from a mean preoperative VAS of 8.0813 to a mean postoperative VAS score of 2.2463 (Table 1). The ODI reductions were equally significant $(P<.0001)$ from a mean preoperative ODI of 47.46 to a mean postoperative ODI score of 13.98 (Table 1). On the surface, the preoperative VAS scores obtained in the authors' study may appear higher than previously reported numbers. In the authors' opinion, this observation is a representation of the fact that endoscopic transforaminal surgery is employed for different indications than translaminar surgery in younger patients who do not receive surgical treatment by traditional surgeons. Hence, their preoperative PROMS, including VAS, are not reported in comparative clinical studies. One of these diverse indications for endoscopic spine surgery in the lumbar spine includes foraminal HNP, which no matter how small may produce pain often out of proportion to its appearance on an advanced cross-sectional imaging study. Toxic annular tears underneath a highly inflamed dorsal root ganglion that can be debrided endoscopically are another such example of a very painful condition affecting younger patients, many of them are in their 30s. In total, the authors have identified 17 validated symptom- atic conditions in the spinal segment, from the central canal to the extraforaminal lateral recess, that are not entirely appreciated by traditional spine surgeons who attempt to decompress the spinal segment but are lacking due to the dependence in indirect decompression and the lack of direct endoscopic visualization of the pain generator in the lateral recess and the foraminal zone. Some of the most prevalent pain generators include (1) an inflamed disc, (2) an inflamed nerve, (3) a hypervascular scar, (4) a hypertrophied superior articular process and ligamentum flavum, (5) a tender capsule, (6) an impacting facet margin, (7) a superior foraminal facet osteophyte, (8) a superior foraminal ligament impingement, (9) a hidden shoulder osteophyte, and many others. ${ }^{29,33,34}$

As an additional objective to enable patients to more easily recall functional outcome measure, preand postoperative walking endurance was recorded, since it may not be obvious to the reader how the ROC plot shows clinically tangible information in terms of improvement of patient functioning with respect to VAS and ODI. Patients reported a statistically significant improvement of walking endurance following the endoscopic decompression procedure, with $77.6 \%$ of patients indicating greater than $5000 \mathrm{~m}$ of walking distance without painessentially an unlimited walking endurance $(P<$ .0001; Table 3). Dichotomization also demonstrated higher walking endurance at a statistically significant level $(P=.002)$ in improved patients when compared to fair patients (Table 4). Walking endurance was also cross-tabulated against PROMs for the 3 observed age groups because of the trimodal instead of normal age distribution observed in our study group (Tables 7 and 8). Only the VAS instrument was able to demonstrate statistically significant associations between low scores $(0$ to 2) and postoperative improvements in walking endurance following the endoscopic decompression procedure (up to $1000 \mathrm{~m}$ or $>5000 \mathrm{~m}$ ) in all 3 age groups (Table 7). This is consistent with the higher accuracy seen with the AUC testing for the VAS score (area 0.926; Table 5A) than with the ODI (area 0.751; Table 6A).

As the determination of MCID is governed by the desired specificity and sensitivity, reporting MCID as a rigid number is of little use to the discussion of endoscopic spinal surgery outcomes. ${ }^{78}$ Ideally, PROM instruments have a sensitivity and a specificity of 1 , which equals a false positive rate 
(1-specificity) of $0 .{ }^{78}$ The upper left corner of the ROC curve is typically closest to this situation. The Youden index is best employed when sensitivity and specificity are diagnostically equally important as desirable with the endoscopic spinal surgery. The optimal cutoff or MCID threshold value is where the Youden index is closest to 1: the ROC curve itself represents it. Given the difficulties in controlling the limitations of the MCID determination described above, the authors of this study recommend reporting these calculated MCID threshold/ cutoff values for the VAS and ODI PROMs with the transforaminal endoscopic surgery as a range. The PSI satisfaction data analysis of this study obtained on patients who successfully underwent the directly visualized outpatient transforaminal endoscopic decompression procedure $92.9 \%$ of the time suggested that meaningful MCIDs for the 2 commonly used PROMs were VAS score reductions ranging from 2.5 to 3.5 and an ODI score reduction between 14 and 17 points. These VAS and ODI MCID numbers are known to be context-specific ${ }^{73}$ and, therefore, needed to be researched for the transforaminal endoscopic procedure in a primary outcome study. The authors could only find 1 study to date - a meta-analysis on full endoscopic decompression for lumbar central and lateral recess stenosis using the interlaminar approach-that investigated the context-specific MCIDs for VAS and ODI. ${ }^{40}$ In the authors' opinion, however, that meta-analysis may have overestimated treatment benefits measured in VAS and ODI reductions (ODI 41.71, 95\% CI 39.80-43.62; VAS leg 5.95, 95\% CI 5.70-6.21; and VAS back 4.22, 95\% CI 3.88-4.56) ${ }^{40}$ since they were statistically significantly higher than the MCIDs reported by its specific studies. In comparison, several original studies employing other types of lumbar decompression procedures for sciatica-type low back and leg pain reported PROM reductions and MCIDs similar to ours. It is conceivable though that these variable numbers are in fact a consequence of a real variability of patients' expectations with this still relatively new operation that is a less-known procedure to the public - a position that has not been researched and independently validated by the authors but should be the focus of future work. The premise of providing sufficient pain relief with early and staged endoscopic surgical pain care with the prospect of that care lasting for years rather than months - as seen with ablation-based interventional spine care- by allowing the natural healing process to occur is a real paradigm shift that is currently being embraced by an increasing number of spine surgeons. This reset of the understanding of the indications and appropriate timing of surgical spine care when employing the transforaminal endoscopic decompression surgery is shifting expectations with patients making the investigation and discussion of MCIDs with commonly used PROMS timely and more relevant than ever.

\section{CONCLUSIONS}

Management of patient expectations by explaining the probability of a successful outcome following the directly visualized transforaminal endoscopic decompression surgery to them is crucially essential to direct spine care safely and efficiently. The MCID ranges for VAS and ODI PROMs found in this study may be used in clinical outcome research involving endoscopic spinal surgery since they were contextspecific to spinal endoscopy and were obtained on patients who specifically sought out endoscopic spine surgeons to treat their sciatica-type low back and leg pain symptoms. The single-integer VAS score had excellent accuracy and was more reliable in capturing patients' judgment of their outcome than the 10-item ODI questionnaire. It is conceivable that the simple VAS score is less susceptible to recall bias or better captures health status improvements relevant to patients who underwent transforaminal endoscopic decompression than the more complex ODI. The VAS could preferably be employed as an easy-tounderstand and more accurate outcome measure by spinal endoscopy patients and their surgeons.

\section{REFERENCES}

1. Lewandrowski KU. Readmissions after outpatient transforaminal decompression for lumbar foraminal and lateral recess stenosis. Int J Spine Surg. 2018;12(3):342-351.

2. Lewandrowski KU. Incidence, management, and cost of complications after transforaminal endoscopic decompression surgery for lumbar foraminal and lateral recess stenosis: a value proposition for outpatient ambulatory surgery. Int $J$ Spine Surg. 2019;13(1):53-67.

3. Lewandrowski KU, Gresser JD, Wise DL, White RL, Trantolo DJ. Osteoconductivity of an injectable and bioresorbable poly(propylene glycol-co-fumaric acid) bone cement. Biomaterials. 2000;21(3):293-298.

4. Markovic M, Zivkovic N, Spaic M, et al. Full-endoscopic interlaminar operations in lumbar compressive lesions surgery: prospective study of 350 patients. "Endos" study. J Neurosurg Sci. 2016.

5. Ruetten S, Hahn P, Oezdemir S, et al. The full-endoscopic 
uniportal technique for decompression of the anterior craniocervical junction using the retropharyngeal approach: an anatomical feasibility study in human cadavers and review of the literature. J Neurosurg Spine. 2018;29(6):615-621.

6. Ruetten S, Komp M, Merk H, Godolias G. Use of newly developed instruments and endoscopes: full-endoscopic resection of lumbar disc herniations via the interlaminar and lateral transforaminal approach. J Neurosurg Spine. 2007;6(6):521530 .

7. Shahidi B, Hubbard JC, Gibbons MC, et al. Lumbar multifidus muscle degenerates in individuals with chronic degenerative lumbar spine pathology, J Orthop Res. 2017;35(12):2700-2706.

8. Tabaraee E, Ahn A, Bohl DD, Phillips FM, Singh K. Quantification of multifidus atrophy and fatty infiltration following a minimally invasive microdiscectomy. Int $J$ Spine Surg. 2015;9:25.

9. Tsou PM, Yeung AT. Transforaminal endoscopic decompression for radiculopathy secondary to intracanal noncontained lumbar disc herniations: outcome and technique. Spine J. 2002;2(1):41-48.

10. Yeung A, Kotheeranurak V. Transforaminal endoscopic decompression of the lumbar spine for stable isthmic spondylolisthesis as the least invasive surgical treatment using the YESS surgery technique. Int J Spine Surg. 2018;12(3):408-414.

11. Yeung AT, Yeung CA. Minimally invasive techniques for the management of lumbar disc herniation. Orthop Clin North Am. 2007;38(3):363-372; abstract vi.

12. Reed CC, Wolf WA, Cotton CC, Dellon ES. A visual analogue scale and a Likert scale are simple and responsive tools for assessing dysphagia in eosinophilic oesophagitis. Aliment Pharmacol Ther. 2017;45(11):1443-1448.

13. Choi G, Prada N, Modi HN, Vasavada NB, Kim JS, Lee $\mathrm{SH}$. Percutaneous endoscopic lumbar herniectomy for highgrade down-migrated L4-L5 disc through an L5-S1 interlaminar approach: a technical note. Minim Invasive Neurosurg. 2010;53(3):147-152.

14. Ercalik T, Gencer Atalay K, Sanal Toprak C, Gunduz $\mathrm{OH}$. Outcome measurement in patients with low back pain undergoing epidural steroid injection. Turk $J$ Phys Med Rehabil. 2019;65(2):154-159.

15. Hermansen E, Myklebust TA, Austevoll IM, et al. Clinical outcome after surgery for lumbar spinal stenosis in patients with insignificant lower extremity pain. A prospective cohort study from the Norwegian registry for spine surgery. BMC Musculoskelet Disord. 2019;20(1):36.

16. Hong X, Shi R, Wang YT, Liu L, Bao JP, Wu XT. Lumbar disc herniation treated by microendoscopic discectomy: prognostic predictors of long-term postoperative outcome. Orthopade. 2018;47(12):993-1002.

17. Lewandrowski KU. "Outside-in" technique, clinical results, and indications with transforaminal lumbar endoscopic surgery: a retrospective study on 220 patients on applied radiographic classification of foraminal spinal stenosis. Int $J$ Spine Surg. 2014;8.

18. Lewandrowski KU. Endoscopic transforaminal and lateral recess decompression after previous spinal surgery. Int J Spine Surg. 2018;12(2):98-111.

19. Jaeschke R, Singer J, Guyatt GH. Measurement of health status. Ascertaining the minimal clinically important difference. Control Clin Trials. 1989;10(4):407-415.
20. Choi G, Pophale CS, Patel B, Uniyal P. Endoscopic spine surgery. J Korean Neurosurg Soc. 2017;60(5):485-497.

21. Gore S, Yeung A. The "inside out" transforaminal technique to treat lumbar spinal pain in an awake and aware patient under local anesthesia: results and a review of the literature. Int J Spine Surg. 2014;8.

22. Komp M, Oezdemir S, Hahn P, Ruetten S. Fullendoscopic posterior foraminotomy surgery for cervical disc herniations. Oper Orthop Traumatol. 2018;30(1):13-24.

23. Liu C, Zhou Y. Percutaneous endoscopic lumbar diskectomy and minimally invasive transforaminal lumbar interbody fusion for recurrent lumbar disk herniation. World Neurosurg. 2017;98:14-20.

24. Liu C, Zhou Y. Comparison between percutaneous endoscopic lumbar discectomy and minimally invasive transforaminal lumbar interbody fusion for lumbar disc herniation with biradicular symptoms. World Neurosurg. 2018;120:e72e79.

25. Ruetten S, Hahn P, Oezdemir S, et al. Full-endoscopic uniportal decompression in disc herniations and stenosis of the thoracic spine using the interlaminar, extraforaminal, or transthoracic retropleural approach. $J$ Neurosurg Spine. 2018;29(2):157-168.

26. Ruetten S, Komp M, Merk H, Godolias G. Fullendoscopic anterior decompression versus conventional anterior decompression and fusion in cervical disc herniations. Int Orthop. 2009;33(6):1677-1682.

27. Ruetten S, Komp M, Merk H, Godolias G. Surgical treatment for lumbar lateral recess stenosis with the fullendoscopic interlaminar approach versus conventional microsurgical technique: a prospective, randomized, controlled study. J Neurosurg Spine. 2009;10(5):476-485.

28. Schubert M, Hoogland T. Endoscopic transforaminal nucleotomy with foraminoplasty for lumbar disk herniation. Oper Orthop Traumatol. 2005;17(6):641-661.

29. Yeung A, Roberts A, Zhu L, Qi L, Zhang J, Lewandrowski KU. Treatment of soft tissue and bony spinal stenosis by a visualized endoscopic transforaminal technique under local anesthesia. Neurospine. 2019;16(1):52-62.

30. Yeung AT. Minimally invasive disc surgery with the yeung endoscopic spine system (YESS). Surg Technol Int. 1999;8:267-277.

31. Yeung AT. The evolution of percutaneous spinal endoscopy and discectomy: state of the art. Mt Sinai J Med. 2000;67(4):327-332.

32. Yeung AT. The evolution and advancement of endoscopic foraminal surgery: one surgeon's experience incorporating adjunctive techologies. $S A S J$. 2007;1(3):108-117.

33. Yeung AT, Gore G. In-vivo endoscopic visualization of patho-anatomy in symptomatic degenerative conditions of the lumbar spine II: intradiscal, foraminal, and central canal decompression. Surg Technol Int. 2011;21:299-319.

34. Yeung AT, Yeung CA. Advances in endoscopic disc and spine surgery: foraminal approach. Surg Technol Int. 2003; 11:255-263.

35. Yeung AT, Yeung CA. In-vivo endoscopic visualization of patho-anatomy in painful degenerative conditions of the lumbar spine. Surg Technol Int. 2006;15:243-256.

36. Siccoli A, Staartjes VE, de Wispelaere MP, Schroder ML. Association of time to surgery with leg pain after lumbar 
discectomy: is delayed surgery detrimental? J Neurosurg Spine. 2019;1-8.

37. McGrath LB, White-Dzuro GA, Hofstetter CP. Comparison of clinical outcomes following minimally invasive or lumbar endoscopic unilateral laminotomy for bilateral decompression. J Neurosurg Spine. 2019;1-9.

38. Martin RL, Kivlan BR, Christoforetti JJ, et al. Minimal clinically important difference and substantial clinical benefit values for the 12-item international hip outcome tool. Arthroscopy. 2019;35(2):411-416.

39. Seuk JW, Bae J, Shin SH, Lee SH. Long-term minimum clinically important difference in health-related quality of life scores after instrumented lumbar interbody fusion for low-grade isthmic spondylolisthesis. World Neurosurg. 2018;117:e493-e499.

40. Lee CH, Choi M, Ryu DS, et al. Efficacy and safety of full-endoscopic decompression via interlaminar approach for central or lateral recess spinal stenosis of the lumbar spine: a meta-analysis Spine (Phila Pa 1976). 2018;43(24):1756-1764.

41. Hijji FY, Narain AS, Bohl DD et al. Risk factors associated with failure to reach minimal clinically important difference in patient-reported outcomes following minimally invasive transforaminal lumbar interbody fusion for spondylolisthesis. Clin Spine Surg. 2018;31(1):E92-E97.

42. Elsayed GA, Dupepe EB, Erwood MS, et al. Education level as a prognostic indicator at 12 months following decompression surgery for symptomatic lumbar spinal stenosis. J Neurosurg Spine. 2018;30(1):60-68.

43. Elkan P, Lagerback T, Moller H, Gerdhem P. Response rate does not affect patient-reported outcome after lumbar discectomy. Eur Spine J. 2018;27(7):1538-1546.

44. Azimi P, Yazdanian T, Benzel EC. Determination of minimally clinically important differences for JOABPEQ measure after discectomy in patients with lumbar disc herniation. J Spine Surg. 2018;4(1):102-108.

45. Andresen AK, Paulsen RT, Busch F, Isenberg-Jorgensen A, Carreon LY, Andersen MO. Patient-reported outcomes and patient-reported satisfaction after surgical treatment for cervical radiculopathy. Global Spine J. 2018;8(7):703-708.

46. Gautschi OP, Stienen MN, Corniola MV, et al. Assessment of the minimum clinically important difference in the timed up and go test after surgery for lumbar degenerative disc disease. Neurosurgery. 2017;80(3):380-385.

47. Asher AL, Chotai S, Devin CJ, et al. Inadequacy of 3month Oswestry Disability Index outcome for assessing individual longer-term patient experience after lumbar spine surgery. J Neurosurg Spine. 2016;25(2):170-180.

48. Adogwa O, Elsamadicy AA, Han JL, Cheng J, Karikari I, Bagley CA. Do measures of surgical effectiveness at 1 year after lumbar spine surgery accurately predict 2-year outcomes? J Neurosurg Spine. 2016;25(6):689-696.

49. Whitmore RG, Curran JN, Ali ZS, et al. Predictive value of 3-month lumbar discectomy outcomes in the NeuroPoint-SD Registry. J Neurosurg Spine. 2015;23(4):459-466.

50. Parker SL, McGirt MJ. Determination of the minimum improvement in pain, disability, and health state associated with cost-effectiveness: introduction of the concept of minimum cost-effective difference. Neurosurgery. 2015;76(Suppl 1):S64 S70.

51. Gum JL, Glassman SD, Carreon LY. Clinically important deterioration in patients undergoing lumbar spine surgery: a choice of evaluation methods using the Oswestry
Disability Index, 36-Item Short Form Health Survey, and pain scales: clinical article. J Neurosurg Spine. 2013;19(5):564-568.

52. Spratt KF. Patient-level minimal clinically important difference based on clinical judgment and minimally detectable measurement difference: a rationale for the SF-36 physical function scale in the SPORT intervertebral disc herniation cohort. Spine (Phila Pa 1976). 2009;34(16):1722-1731.

53. Lewandrowski KU. Retrospective analysis of accuracy and positive predictive value of preoperative lumbar MRI grading after successful outcome following outpatient endoscopic decompression for lumbar foraminal and lateral recess stenosis. Clin Neurol Neurosurg. 2019;179:74-80.

54. Lewandrowski KU. Successful outcome after outpatient transforaminal decompression for lumbar foraminal and lateral recess stenosis: the positive predictive value of diagnostic epidural steroid injection. Clin Neurol Neurosurg. 2018;173:3845.

55. Pfirrmann CW, Metzdorf A, Zanetti M, Hodler J, Boos N. Magnetic resonance classification of lumbar intervertebral disc degeneration. Spine (Phila Pa 1976). 2001;26(17):18731878.

56. Schroeder GD, Kurd MF, Vaccaro AR. Lumbar spinal stenosis: how is it classified? J Am Acad Orthop Surg. 2016;24(12):843-852.

57. Lee DY, Shim CS, Ahn Y, Choi YG, Kim HJ, Lee SH. Comparison of percutaneous endoscopic lumbar discectomy and open lumbar microdiscectomy for recurrent disc herniation. J Korean Neurosurg Soc. 2009;46(6):515-521.

58. Hasegawa T, An HS, Haughton VM, Nowicki BH. Lumbar foraminal stenosis: critical heights of the intervertebral discs and foramina. A cryomicrotome study in cadavera. $J$ Bone Joint Surg Am. 1995;77(1):32-38.

59. Yeung AT, Lewandrowski KU. Retrospective analysis of accuracy and positive predictive value of preoperative lumbar MRI grading after successful outcome following outpatient endoscopic decompression for lumbar foraminal and lateral recess stenosis. Clin Neurol Neurosurg. 2019;181:52.

60. Sengupta DK, Herkowitz HN. Lumbar spinal stenosis. Treatment strategies and indications for surgery. Orthop Clin North Am. 2003;34(2):281-295.

61. Hoogland T, van den Brekel-Dijkstra K, Schubert M, Miklitz B. Endoscopic transforaminal discectomy for recurrent lumbar disc herniation: a prospective, cohort evaluation of 262 consecutive cases. Spine (Phila Pa 1976). 2008;33(9):973-978.

62. Hoogland T, Schubert M, Miklitz B, Ramirez A. Transforaminal posterolateral endoscopic discectomy with or without the combination of a low-dose chymopapain: a prospective randomized study in 280 consecutive cases. Spine (Phila Pa 1976). 2006;31(24):E890-E897.

63. Tsou PM, Alan Yeung C, Yeung AT. Posterolateral transforaminal selective endoscopic discectomy and thermal annuloplasty for chronic lumbar discogenic pain: a minimal access visualized intradiscal surgical procedure. Spine $J$. 2004;4(5):564-573.

64. Fairbank J. Use of Oswestry Disability Index (ODI). Spine (Phila Pa 1976). 1995;20(13):1535-1537.

65. Fairbank JC, Pynsent PB. The Oswestry Disability Index. Spine (Phila Pa 1976). 2000;25(22):2940-2952.

66. van Hooff ML, Spruit M, Fairbank JC, van Limbeek J, Jacobs WC. The Oswestry Disability Index (version 2.1a): 
validation of a Dutch language version. Spine (Phila Pa 1976). 2015;40(2):E83-E90.

67. van Hooff ML, Mannion AF, Staub LP, Ostelo RW, Fairbank JC. Determination of the Oswestry Disability Index score equivalent to a "satisfactory symptom state" in patients undergoing surgery for degenerative disorders of the lumbar spine-a Spine Tango registry-based study. Spine J. 2011;16(10):1221-1230.

68. Macnab I. Negative disc exploration. An analysis of the causes of nerve-root involvement in sixty-eight patients. $J$ Bone Joint Surg Am. 1971;53(5):891-903.

69. Macnab I. The surgery of lumbar disc degeneration. Surg Аппи. 1976;8:447-480.

70. Macnab I, St Louis EL, Grabias SL, Jacob R. Selective ascending lumbosacral venography in the assessment of lumbar-disc herniation. An anatomical study and clinical experience. J Bone Joint Surg Am. 1976;58(8):1093-1098.

71. Mancuso CA, Salvati EA, Johanson NA, Peterson MG, Charlson ME. Patients' expectations and satisfaction with total hip arthroplasty. J Arthroplasty. 1997;12(4):387-396.

72. Hajiro T, Nishimura K. Minimal clinically significant difference in health status: the thorny path of health status measures? Eur Respir J. 2002;19(3):390-391.

73. Beaton DE, Boers M, Wells GA. Many faces of the minimal clinically important difference (MCID): a literature review and directions for future research. Curr Opin Rheumatol. 2002;14(2):109-114.

74. Lauridsen HH, Hartvigsen J, Manniche C, Korsholm L, Grunnet-Nilsson N. Responsiveness and minimal clinically important difference for pain and disability instruments in low back pain patients. BMC Musculoskelet Disord. 2006;7:82.

75. Chung AS, Copay AG, Olmscheid N, Campbell D, Walker JB, Chutkan N. Minimum clinically important difference: current trends in the spine literature. Spine (Phila $\mathrm{Pa}$ 1976). 2017;42(14):1096-1105.
76. Copay AG, Chung AS, Eyberg B, Olmscheid N, Chutkan N, Spangehl MJ. minimum clinically important difference: current trends in the orthopaedic literature, part I: upper extremity: a systematic review. JBJS Rev. 2018;6(9):e1.

77. Copay AG, Eyberg B, Chung AS, Zurcher KS, Chutkan N, Spangehl MJ. Minimum clinically important difference: current trends in the orthopaedic literature, part II: lower extremity: a systematic review. JBJS Rev. 2018;6(9):e2.

78. Cook CE. Clinimetrics corner: the minimal clinically important change score (MCID): a necessary pretense. J Man Manip Ther. 2008;16(4):E82-E83.

79. Metz CE. Basic principles of ROC analysis. Semin Nucl Med. 1978;8(4):283-298.

Disclosures and COI: The views expressed in this article represent those of the authors and no other entity or organization. The authors have no conflict of interest in regards to this research.

Corresponding Author: Kai-Uwe Lewandrowski, MD, Center for Advanced Spine Care of Southern Arizona and Surgical Institute of Tucson, 4787 E Camp Lowell Dr, Tucson, AZ 85712. Phone: (520) 204-1495; Email: business@tucsonspine.com.

Published 30 April 2020

This manuscript is generously published free of charge by ISASS, the International Society for the Advancement of Spine Surgery. Copyright (C) 2020 ISASS. To see more or order reprints or permissions, see http://ijssurgery.com. 